\title{
The Anthropocentric Needs of
}

\section{Academic Librarianship}

\author{
BY DANIEL P. BERGEN
}

IT IS HISTORICALLY CHARACTERISTIC of the elite colleges and universities like Swarthmore, Harvard, Amherst, and Princeton that, unlike their lower-quality brethren, they have been able to assume, on the part of their students, the motivation for much self-learning with a minimum of formal faculty intervention. In our day, alarming projections of enrollment and of the available supply of competent teachers are forcing less distinguished institutions to appropriate this "Ivy League" presupposition. The application of communication media to problems of knowledge transmission in higher education has already resulted in a better allocation of available faculty resources. At the same time, the proliferation of independent study programs and the rise of undergraduate courses incorporating instruction in the techniques of research manifest faculty interest in individualizing instruction or, put another way, in making the student himself the learner.

Throughout the first half of our century, lecturing professors armed with textbook compendia kept the classroom the primary locale of learning. In response to societal and graduate school pressures, the intervening years have seen remarkable changes in the configuration of undergraduate education. As professors increasingly insist that seminars, tutorial confrontations, sessions with teaching machines, and encounters with educational television be supplemented by extensive outside reading, the library, as a learning locale, assumes more importance. Substantially increased human activity in academic libraries
Mr. Bergen is a doctoral candidate in the Graduate Library School, University of Chicago.

seems circumstantially ordained by more than the fact of rising enrollments. At least one of our colleagues, Eileen Thornton of Oberlin who, as librarian of a research-oriented liberal arts college, is in excellent position to observe the trends discussed, has expressed concern over the implications of "turning the student loose in the library to do more for himself." 1 The problem, thus identified, has a strong human cast. The satiation of this human milieu demands of academic librarianship an increased sensitivity to the psychic needs of those it serves.

It may be useful to view the academic library as an institution within an institution, that is, as an institution comprehended by a college or university which provides for it, at any given moment, an operating context. Unlike a subject department which has prime responsibility for a specified student group, the library must directly serve an allcampus constituency. It has been suggested elsewhere that academic libraries can afford little lag in responding to a composite change in the psychological orientation of the students they serve. ${ }^{2}$ Ongoing adaptation of this kind hinges upon a continuous assessment of ecological forces playing upon the library.

1 Thornton, "Libraries in Smaller Institutions of Higher Education," Library Trends, X, (October $1961), 197$.

2 See Daniel P. Bergen, "Socio-Psychological Research on College Environments," CRL, XXIII, (November 1962), 473-81. 
Such an approach, oriented to the structuring of library conditions and services on a stimulus-response basis, lacks the long-term impact and overarching quality of more comprehensive perspectives. For such perspectives, there is need to apply what social scientists call the cultural and behavioral approaches to social understanding.

Canonically, the cultural approach permits one to view youth of college age as comprising a subculture of the national culture. ${ }^{3}$ In the behavioral usage, the focus is on students as individuals, their reflections on the Larger Society and the operating locale, and how these perceptions condition the character of their relations with other students, teachers, and even librarians. ${ }^{4}$ An analytical beginning may be made by examining the subcultural uniqueness of students who frequent academic libraries.

It may be hypothesized at the outset that youth, as the period separating childhood from adulthood, be defined in two ways: (1) youth as apprenticeship for social and occupational mobility and (2) youth as a time of participation in a unique "youth culture." 5 In the former conception, which had greater relevance in the earlier, more deprived years of our century (though even now found prevailing on occasion), the period of youth was spent girding oneself for an "Horatio Alger" rise to the top. Because the trip to the top began in a college, such an institution was analogically viewed by its inhabitants as approximating the Pennsylvania Railroad Station. ${ }^{6}$ If, on the other hand, students in eastern seaboard colleges and universities accurately articulate sentiments common to youth the nation over, then the latter view of youth as defined by "youth cul-

\footnotetext{
"Otis Dudley Duncan and Leo F. Schnore, "Cultural, Behavioral, and Ecological Perspectives in the Study of Social Organizations," American Journal of Sociology, LXV, (September 1959), 134.

4 Ibid.

"Kenneth Keniston, "American Students and the 'Political Revival,'" American Scholar, XXXII, (Winter 1962-1963), 44.

Quoted in Ibid., p.46. The phrase is Edgar Frien. denberg's.
}

ture" seems more worthy of extended discussion.

According to Kenneth Keniston, a member of the psychiatric staff of the Yale Medical School, the post-WorldWar-II period has witnessed the emergence of a common youth culture, the members of which "are expected to behave in special, idiosyncratic ways that are symbolic of their age." 7 In a nation where the transition from childhood to adulthood is prolonged and ritually unmarked, the thrift and determination which powered the upward drive of youth apprentices are being replaced by requisites of the youth culture like "a B.A., a certain personal sophistication, specialized technical competence, an acceptable wife and at least a good imitation of a 'genuine interest in people." "8 The major common characteristic of the youth culture is, without question, the internal alienation of youth from the values of the Larger Society, a condition so vital to this analysis that it demands further elaboration.

Generically speaking, alienation refers to "the increasing distance between men and their former objects of love, commitment, loyalty, devotion, reverence." 9 It implies a repudiation of certain values or activities of the Larger Society which results in feelings of "nonbelonging" or "non-sharing." Professor Melvin Seeman of UCLA has conceived it very aptly as a social-psychological point of view. ${ }^{10}$ Processes like exclusiveness, subordination, discontinuity, and discrepancy, while not validly equated with alienation, tend to promote it. ${ }^{11}$

Five variants of alienation have been identified: (1) powerlessness ("the expectancy or probability held by the individual that his own behavior cannot

\footnotetext{
${ }^{7}$ Ibid., p.48.

${ }^{8}$ Ibid., p.47.

- Keniston, "Alienation and the Decline of Utopia," American Scholar, XXIX, (Spring 1960), 161.

${ }_{10}$ Seeman, "On the Meaning of Alienation," American Sociological Review, XXIV, (December 1959), 784 11 Hajda, "Alienation and Integration of Student Intellectuals," American Sociological Review, XXVI, (October 1961), 762.
} 
determine the occurrence of the outcomes, or reinforcements, he seeks."); (2) meaninglessness ("the individual is unclear as to what he ought to believewhen the individual's minimal standards for clarity in decision-making are not met . . . it is characterized by a low expectancy that satisfactory predictions about future outcomes of behavior can be made."); (3) normlessness ("a high expectancy that socially unapproved behaviors are required to achieve given goals."); (4) isolation ("assign low reward value to goals or beliefs that are typically highly valued in the given society."); and (5) self-estrangement (in the Sane Society, Erich Fromm writes: “. . . a mode of experience in which the person experiences himself as an alien. He has become, one might say, estranged from himself."). ${ }^{12}$ In particular persons, alienation is usually reflected as a mixture of these five variants and tends to differ markedly in scope and intensity. It will be most convenient, for the time being, to continue to regard the referent in alienation as the Larger Society, all the time recognizing the alienative impact which particular social institutions, like libraries, can have on those who utilize them.

If one were to identify the most fundamental cause of the alienation in youth culture it would be the high discontinuity between growth stages (i.e., childhood, youth, and adulthood) in our highly technical, skills-devouring society. In the developing nations, where ceremonials smooth the interstage transition, there is low discontinuity and an improvement in what Jan Hajda calls "social and normative self-integration." 13 To the youth culturalist the world of the child appears "integral, concrete, immediate, and spontaneous" while adult life seems "dissociated, abstract, specialized, and conformist." 14 Neither image

\footnotetext{
12 Seeman, op. cit., pp.784, 786, 788, 789.

13 Hajda, op, cit., p.760

14 Keniston, op. cit., p.166. Kaspar D. Naegele sug. gests that in this period of self-containedness, "child.
}

satisfies youth and both are rejected. Nor is the world of ideas always an answer to the youth's needs for commitment, given the strong climate of skepticism created by so many intellectuals. ${ }^{15}$

The above conditions make it less difficult for us to believe that alienation is not so much something which is forcibly imposed upon youth as the alternative that, through youth's eyes, has the greatest measure of realism. Collegeage youth, one suspects, are in a period in which even some of the adolescent values of the high school years no longer seem relevant. While the high school assets of personality, reputation, ${ }^{16}$ looks, athletic ability, clothes, and activities participation still influence college student behavior, there would seem to be a progressive waning of their importance among the participants in higher education.

Youth is difficult to understand precisely because it is a period of covert attachments, attachments which are submerged and frequently impossible to identify in manifest individual behavior. Youth, suggests Erik Erikson, undergo a "psycho-social moratorium," a period of institutionalized indecision which has the a priori approval of society. At the end of this time, youth are expected to decide where or even whether they will fit into the adult system. ${ }^{\mathbf{1 7}}$

It is understandable that youth should renounce the values of childhood. More difficult to comprehend is youth's reluctance to identify with the adult world. Keniston is persuaded that in the relatively few instances where youth choose adult models the decision is diffi-

\footnotetext{
hood looks long ago, and the promised land is only partly visible in the shape of contemporary adults." See his "Youth and Society: Some Observations," Daedalus, LXXXXI, (Winter 1962), 51 .

15 Keniston, "Social Change and Youth in America," Daedalus, LXXXXI, (Winter 1962), 170. As Keniston puts it: ". . . there has seldom been as great a confusion about what is valid and good as there is now. .." See his "Alienation and the Decline of Utopia," pp.i61-62.

is James C. Coleman, The Adolescent Society: The Social Life of the Teenager and Its Impact on Education (New York: Free Press of Glencoe, 1961), pp.40, 44. 48 .

i7 Keniston, "American Students . . ." American Scholar, XXXII, 52 .
} 
cult because of the ambiguity imparted to adult roles by the rapidity of social and technological change. ${ }^{18}$ For example, the circulation librarian in a conventional academic library may function as the overseer of black boxes, rather than the overseer of people, with the automation of that library. In general, there is a coolness and lack of enthusiasm in youth vis-a-vis the adult world. Indeed the relative lack of rebelliousness in youth toward adults would suggest that the internalized value system of the former seldom adopts a competitive stance with respect to the externalized values of the latter. ${ }^{19}$ At Sarah Lawrence college, where one might anticipate much sibling-parent conflict because of the school's strong press for independence of thought and behavior, ${ }^{20}$ such conflicts did not appear to be leading generators of student anxiety. ${ }^{21}$

The irrelevance of parental models causes young people to arrive at college in search of more credible exemplars. Keniston has proposed that where a reasonable amount of academic interest already exists in students, a professor who is expansive and in possession of the right amounts of social and political sensitivity can do much to reconstruct commitment in those with whom he has contact. ${ }^{22}$ It is expected, conversely, that nar-

\footnotetext{
18 Keniston, "Alienation . . " American Scholar, XXIX, 166. For a discussion of the problem of identification given an ambiguous referent, see Talcott Parsons, "Youth in the Context of American Society," Daedalus, LXXXXI, (Winter 1962), 119.

10 Reuel Denney, "American Youth Today: A Bigger Cast, A Wider Screen," Daedalus, LXXXXI (Winter $1962), 134$. Denney notes that the relationship between the father and son (James Dean) in Rebel Without $a$ Cause was "unsatisfactory because it was marked by slackness rather than moral tension."

${ }^{20}$ Esther Raushenbush, "The Climate of Sarah Lawrence College" in Achievement in the College Years: $A$ Record of Intellectual and Personal Growth (New York: Harper, 1960), pp.21-57.

^ Mary Collins, "The College Experience through the Eyes of Students," Ibid., pp.85-86. Sarah Lawrence girls were asked to check those items on a 47 -item scale which caused them worry or anxiety. The results were as follows: (1) 30 per cent checked "Conflict with your mother" (7th from the top); (2) 29 per cent checked "Family wants you to be more dependent than you are" (11th from the top); (3) 24 per cent checked "Too emotionally dependent on family" (18th from the top); (4) 21 per cent checked "Conflict with from the top); (4) 21 per cent checked "Conflict with checked "Political disagreement with the family" (43rd from the top).

"Keniston, "American Students . . ."American Scholar, XXXII, pp.63-64.
}

row, subspecialized pedantry tends to reinforce alienation in students. It is undoubtedly true that the excitement of commitment in students demands a rare kind of selfless altruism. Such a humane teacher is, to use Joseph Adelson's phrase, a "mystic healer," that is, one who "concentrates neither on himself, nor the subject matter, nor on the discipline, but on the student, saying: 'I will help you become what you are." "23 Curiously, those teachers who are not too obviously perceptive, original, and intellectually powerful will probably make the best models. David Riesman has warned, certainly legitimately, that the exaggeration of such charismatic qualities may make students fearful of being overly influenced. ${ }^{24}$ It may be worthwhile, at this point, to reflect on whether librarians, especially those directly serving the public, possess these humane qualities so vital to the deterrence of alienation.

Empirical studies of librarian personality have been completed by both Robert R. Douglass and Alice I. Bryan. Douglass' doctoral dissertation at the University of Chicago entitled "The Personality of the Librarian" involved students still enrolled in graduate schools of librarianship. The Public Librarian, Miss Bryan's contribution to the Public Library Inquiry, assessed the personalities of practicing librarians. Dean Douglass concluded that those in training for librarianship were highly conservative, conformist, weak in qualities of ascendance, motivation, and drive, and, most significantly, "aloof and impersonal with respect to people." 25 Comparing male public librarians with a control group of male university students, Miss Bryan determined that vis-à-vis the control group the librarians were "sedentary,"

${ }^{23}$ Adelson, "The Teacher as Model" in Nevitt Sanford (ed.), The American College: A Psychological and Social Interpretation of the Higher Learning (New York: Wiley, 1962), pp.411-12.

a Riesman, "Student Culture and Faculty Values" in Spotlight on the College Student (Washington: American Council on Education, 1959), p.13.

${ }_{25}$ As reported in Alfred L. Brophy and George M. Gazda, "Handling the Problem Staff Member," Illinois Libraries, XLIII, (December 1961), 755. 
"less likely to show qualities of leadership," and, on balance, lacking confidence and feeling a burden of inferiority. ${ }^{26}$

In the six-orientation typology developed by Alexander W. Astin and John L. Holland for the Environmental Assessment Technique (EAT), librarians were categorized "conventional." According to the construction of these two investigators, the librarian "prefers structured numerical and verbal activities and subordinate roles," "conforms," and "identifies with power, externals, and status." 27 Of those disciplines normally taught in a college or university, only accounting, business education, and economics shared this orientation. The humanities were concentrated, by and large, in the artistic orientation; the social sciences were split between the social and enterprising orientations; and the physical sciences fell mainly within the intellectual orientation.

Further evidence of teacher-librarian incongruity comes from a recent survey by the Center for the Study of Higher Education at the University of California (Berkeley). The center sought opinions from librarians on two classroom teaching practices: (1) the discussion of controversial social issues and (2) the expression of personal viewpoints by instructors on traditional values. The data, when analyzed, revealed that "librarians are likely to be marginal members of the academic community" and "to the extent to which this is in fact the case librarians are less apt than administrators or teachers to share academic views about these practices, and are more apt to take on the orientation of the general public." 28

From the foregoing, two conclusions would seem warranted: (1) that librar-

26 As reported, Ibid., p.753.

27 Astin and Holland, "The Environmental Assessment Technique: A Way to Measure College Environments," Journal of Educational Psychology, LII, (December 1961), 310.

December 1961), 310. "Herbert Maccoby, "Controversy, Neutrality, and Higher Education," American Sociological Review, XXV, (December 1960), 889. ians are not likely to possess the personal warmth and humanity which would inspire commitment in alienated college youth and (2) that librarians do not generally share with their teaching colleagues the academic ethos, that is, the set of values, beliefs, and attitudes toward things academic which has model validity for youth if possessed by the altruistic teacher. The pessimism of these conclusions, however, should prompt one to emphasize their 'seemingness."

Remedial strategy is available to both library administrators and educators. For their part, those charged with assigning library personnel should, through the skillful use of personality tests and interviews, assure at least a minimum degree of congeniality between those placed in public service positions and the academic library's youthful patrons. The above suggestion may seem utopian in an era of personnel shortages, however, the author is convinced that a better rationale than incumbent wishes could be devised for determining who should occupy such positions. From here it would also seem desirable for library schools to provide their students with some background in the psycho-biological foundations of human development and behavior. Such a foundation is necessary because, as Kasper Naegele has pointed out, those serving youth must generate images of youth "while no longer belonging to youth."'29 Just as the emerging profession of social service attempts to recruit persons who can relate themselves well to a diverse clientele, so, it would seem, should academic librarianship try to enlist persons of adaptability and congeniality who are as conversant with the elements of human relations as they are knowledgeable about the books which they manipulate. If, as Reuel Denney has suggested, many teaching academicians "have a vested interest

20 Naegele, op. cit., p.57. 
in books as beleaguered and dutiful," 30 then it may be said that the truly anthropocentric librarian displays his interest in humanity by viewing collections of books as accessible and pleasurable.

Mitigation of the marginal ${ }^{31}$ position now occupied by librarians with respect to the academic enterprise can be accomplished only through an increase in faculty-librarian interaction, particularly at the informal level. ${ }^{32}$ The capacity to make such associations is developed by librarians who (1) are willing to devote the time required for the acquisition of fundamental knowledge in one or several subject disciplines and (2) do not see a threat to their autonomy in the making of friendly overtures to the teaching faculty. Support for the first point comes from an overview of recent literature on education for librarianship where there is quite obviously a growing consensus regarding the need to produce academic librarians with subject competence. And it should be understood that subject competence need not imply the ability to do basic research in a discipline. Very recently, the Committee on Academic Status of the University Librarians Section of the ACRL has accepted the research criterion for purposes of promotion and the equation of library positions with academic ranks. ${ }^{33}$

While research is the accepted norm

${ }^{30}$ As quoted in Riesman, The Oral Tradition, The Written Word, and the Screen Image (Yellow Springs, Ohio: Antioch Press, 1956), pp.22-23.

a For an excellent discussion of psychological marginality, see Riesman, "Some Observations Concerning Marginality" in his Individualism Reconsidered and Other Essays (New York: Free Press of Glencoe, 1954), p.154.

${ }^{32}$ Over a decade ago, Lawrence Clark Powell could comment: "On every library staff I have any acquaintance with, I can count on a few fingers the number of persons who can establish intellectual camaraderie with the faculty." See his "Education for Academic Librarianship" in Bernard Berelson (ed.), Education for Librarianship: Papers Presented at the Library Conference, University of Chicago, August 16-21, 1948 (Chicago: ALA, 1949), pp.133-46.

${ }^{33}$ Árthur M. McAnally, "Privileges and Obligations of Academic Status," CRL, XXIV, 106. Neal Gross of Harvard, a student of the organizational problems in higher education, has recently pointed out that "al. though the reward system of the university stresses research and scholarly productivity the social arrangements of the university for most faculty members are not conducive to the effective accomplishment of this not conducive to the effective accomplishment of this of its own for the research function. Its budgets are basically teaching budgets and so the faculty members are forced to go outside the university to the founda- of progress in universities, one wonders about the status of teacher-librarian integration, based on the sharing of subject knowledge, if, as seems implicit in the committee's proposals, most librarian research is concentrated in the field of librarianship (e.g., Arthur McAnally contends that research librarian positions should be established). Moreover, is it not logical to be more optimistic about the motivation of librarians to acquire knowledge of some depth in a traditional discipline than about their drive to become professional researchers, even in their own field? There are undoubtedly many who have selected a library career in order to avoid the research responsibilities of the university professor. While recognizing the requirement for more operational research in academic librarianship, one cannot help but feel that the subject-qualified librarian, capable of intellectual intercourse with his teaching associates, will be best able to carry over into the library the creative tension of the great teacher's classroom.

Another major characteristic of the youth culture is its familism, that is, the tendency of its participants to seek privacy within the manageable confines of the family. ${ }^{34}$ Rather than face the pressing issues of the Larger Society, youth have issued a manifesto of parochialism in which, according to David Riesman, they express preference for the "postcollegiate fraternity of the small suburbs." 35 Indeed, an analysis of questionnaires from three thousand boys and girls (ages 14-22) at work, in high school, and at seventy-eight colleges and universities

tions, to industry, or to the federal government primarily for support of their research activities." See Neal Gross, "Organizational Lag in American Universities," Harvard Educational Review, XXXIII (Winter 1963), 68. It may be suggested that imposing the research criterion on librarians may cause them to become less oriented to the institutions in which they work. Like the "cosmopolitans" in Alvin Gouldner's analysis of "cosmopolitans" and "locals," they may begin to look to associates in the field rather than their local superiors for their advancement. See Alvin Gouldner, "Cosmopolitans and Locals: Toward an Analysis of Latent Social Poles (Part I)," Administrative Science Quarterly, II, (January 1958), 280306 .

is Riesman, op. cit., p.14.

as Riesman, "Where is the College Generation Headed?," Atlantic, April 1961, 40. 
forced George Gallup and Evan Hill to conclude that:

Our typical youth will settle for low success rather than risk high failure. He has little spirit for adventure. He wants to marry early-at twenty-three or twenty-four-after a college education. He wants two or three children and a spouse who is 'affectionate, sympathetic, considerate and moral'; rarely does he want a mate with intelligence, curiosity or ambition. He wants a little ranch house, an inexpensive new car, a job with a large company, and a chance to watch TV each evening after the smiling children are asleep in bed. ${ }^{36}$

The Gallup-Hill characterization is supported by the findings of two previous studies: (1) Time magazine's 1955 survey of seniors at twenty colleges and (2) a study of women undergraduates sponsored by Mademoiselle magazine in 1954.37

While the majority of youth do not overtly reject society and become beatniks or "angry young men," 38 it is apparent from the foregoing that, for most, the dolce vita belongs to the private. In this private or inner world to which youth migrate there exists a strong tendency to seek sensual gratification in the here and now or, in Keniston's lexicon, "a kind of hedonism of the moment." 39 This contemporaneity is so powerful that most youth are little obsessed with past commitments or future planning, beyond graduate school. ${ }^{40} \mathrm{~A}$ critical consequence

36 Gallup and Hill, "Youth: The Cool Generation," Saturday Evening Post, December 23-30, 1961, 64.

${ }^{37}$ Reported and discussed in Riesman, "The Found Generation," American Scholar, XXV, (Autumn 1956), 429,432 . Riesman observed that in the Time survey, it was the exception for a student to say more about his intended career than about his prospective wife and family. The women undergraduates questioned in the Mademoiselle study revealed a fear of ambition in themselves and in their prospective spouses.

s Denney, op. cit. p.158. According to Denney, to be "beat" implies "the shallowest commitment of one's self and the broadest satire on the rat race." For a further discussion of overt social deviance, see David Matza, "Subterranean Traditions of Youth," Annals of the American Academy of Political and Social Science, CCCXXXVIII, (November 1961), 102-18.

$\Im$ Keniston, op. cit., p.48. See also what Philip E. Jacob suggests about the feelings which prevail among 75 per cent to 80 per cent of American college students in his Changing Values in College: $A n$ Exploratory Study of the Impact of College Teaching (New York: Harper, 1957), p.1.

to Francis Golffing has made an interesting analogy of this privatism is that, with the exception of an activist minority, students find more meaning in immediately controllable activities like taking part in a play, listening to music, spending a week-end with friends, or even dating a steady girl than in trying to understand and act upon the vital issues of society.

When confronted with really pervasive issues, a "social powerlessness" overtakes youth. This sense of incapacity is reflected in the novels and short stories of those authors currently enjoying popularity among young people. Salinger, Updike, and Walker Percy, among others, center not upon the life-sized problems of the macrocosm, but on the microcosmic issues of everyday life. ${ }^{41}$ One Southern boy, responding to the survey by Gallup and Hill, accurately articulated these feelings when he submitted that, in the absence of great heroes, all important work was completed by highly specialized teams of men. ${ }^{42}$

Needless to say, there are important implications of youth's withdrawal from the public domain. Being in society but not for society creates, over the long term, an untenable dichotomy. The deliberate failure to recognize the reality and importance of the nonprivate world can result in severe psychological tension. ${ }^{43}$ Because it restrains students from seeking new worlds to conquer, feelings of social powerlessness might even cause a vast waste of talent. As Keniston has contended: “. . . an alienated generation seems too great a luxury in the 1960's. To cultivate one's garden is a stance most appropriate in times of peace and calm, and least apposite to an era of desperate international crisis." 44

between present day youth's quest for experience qua experience and the "mild and intellectualized" hedonism of the Alexandrine Age. See his "The Alexandrine Mind," Partisan Review, XXII, (Winter 1955), 43-82. «Time magazine, for example, calls Salinger's Catcher in the Rye "a brilliant and intensive vision of Catcher in the Rye "a brilliant and intensive vision of
a very few compass degrees of experience." See "The
Sustaining Stream," Time, (February 1, 1963), 84. ${ }^{42}$ Gallup and Hill, op. cit., p.66.

4 Keniston, "Social Change. . ." Daedalus, LXXXXI, 166-67.

4 Ibid., p.167. 
It has already been suggested that academic librarians, particularly those dealing with users, can do their part toward counteracting alienation by adopting attitudes toward youth which do not proceed from false or unrealistic assumptions about youth's character. It may also follow, from what has been said about privatism and social powerlessness as components of alienation, that the physical structure of libraries could represent a countervailing force.

A beginning may be made by designing libraries, and interiors, over which student users can feel some measure of control. If the cavernous main reading rooms and gothic towers of libraries constructed during the early part of the twentieth century reflected our reverent attitude toward knowledge, as Ralph Ellsworth has suggested, ${ }^{45}$ then our present attempt might be to put up buildings which combat the feelings of alienation inspired by the older, awe-eliciting structures. One might propose a library with diverse environments scientifically structured, a library in which a student with a locally average alienation profile could move from smaller to larger rooms, and through rooms with varying configurations, with little corresponding loss in his perception of control over the situation. The instruments thus far devised for assessing alienation within a social system will be discussed a bit later. It suffices to say for the moment that the programing of a library's interior and exterior demands systematic information on those who will use it.

Only infrequently in the past have academic librarians given consideration to the common psychological characteristics of youth in their plans to improve operations. A striking thing about E. Walfred Erickson's overview of academic library surveys for the period

4 Ellsworth, Library Buildings (Volume 3, Part 1) in Ralph R. Shaw (ed.), The State of the Library Art (New Brunswick, New Jersey: Rutgers-The State University, Graduate School of Library Service, 1960), p.104.
1938-52 is the almost complete absence of data regarding human and psychic factors, a lack which may be more directly related to the nonavailability of measuring instruments than to a lack of concern for such matters on the part of the surveyors. Clearly, if an academic library survey is "a scientific collection and analysis of data pertaining to the operation of a particular library" 46 and if, as Ellsworth has observed, "each new library tends to be a law unto itself," 47 then the failure to consider psychological factors is to deny a body of information which may possess significant relevance for the sophistication of library operations.

An understanding of the ebb and flow of the alienative and integrative tendencies in a student body could certainly influence, in conjunction with factors of economy and efficiency, the positioning of the movable elements in a modular library building. For example, where high alienation prevails, reading areas might be restricted to the low-ceiling periphery of the upper floors of a building, where, through an abundance of glass, students may look down upon the campus panorama below. The alienated could profit from a vista like that provided by a fifth-floor student study on the north side of the all-glass library unit in the recently erected University of Chicago law quadrangle.

The late Frank Floyd Wright was convinced that to be truly civilized a building had to be organically linked with its physical environment. ${ }^{48}$ It does not seem such a crude analogy, then, to propose that psychic costs will be minimized in those libraries which respond structurally to the perception needs of their student clienteles.

It is unfortunate, but true, that on most campuses library designers must

46 Erickson, College and University Library Surveys: 1938-1952 (ACRL Monograph No. 25) (Chicago: ALA, 1961), p.1.

4 Wright, $A n$ Autobiography (New York: Duell, Sloan and Pearce, 1943), pp.326, 338. 
contend with a strong press for low-cost functionalism in the building to be constructed. With money in short supply, many college and university administrators must content themselves with new library buildings which do little more than satisfy the physical norms of economy and efficiency. It is a fact, however, that what is efficient physically may be less propitious for the psyche. An architect writing for librarians has noted that "it is difficult to persuade ourselves that there is usefulness to what is not immediately and apparently useful to us." 49

It is difficult to concur, considering the above, with Ellsworth's argument that a library should look like what campus habitués are used to visualizing as a library. ${ }^{50}$ If to look like a library demands that space be rectilinearly enclosed, then one might take issue with the continuing construction of libraries that look like libraries. Rectilinear structures have great utility, to be sure, but what really stimulates the mind, as Robin Boyd has pointed out, are buildings characterized by space enclosed by curved structures, even by structures which curve in opposing directions. ${ }^{51}$ The real constant in modular building, therefore, is how interestingly its fixed external shell encloses its flexible interior.

It is the exterior which dominates a modular library for its lifetime, consequently the composite of that exterior should be inviting and meaningful for students burdened with an alienation unhappily born of choice. Obviously $\operatorname{cog}$ nizant of the human elements in the library's situation, the chairman of the department of architecture at Carnegie Institute of Technology has concluded that "if utility is our one objective we'll do better in the days ahead to go underground." 52

49 Paul Schweikher, "The Space in Between" in Guidelines for Library Planners: Proceedings of the Library Building and Equipment Institute (1959) (Chicago: ÁLA, 1960), p.8.

${ }^{50}$ Ellsworth, op. cit., p.104.

51 Boyd, "The Counter-revolution in Architecture,"

Harper's, September $1959,45$.
52 Schweikher, op. cit., p.7.
The design of a library's interior involves the constant reconciliation of technical operating requirements with psychological needs of not only the users but of the library staff as well. To suggest, as did the Program for an Undergraduate Library at the University of Michigan, that the UGL should be "inviting and pleasant ... friendly, beautiful, and informal rather than imposing" 53 is to operate on a high level of abstraction, meaningless without the excellent specification subsequently given these concepts in the Michigan program.

It is imperative to understand that the sense of beauty is an individual experience. A library which is pleasant, inviting, and beautiful in the perspective of one student may possess opposing characteristics in the view of another. The most carefully designed and psychologically informed library imaginable will seem distasteful to some persons on campus. A library interior will seem congenial to the majority, however, if its arrangement is based upon a composite assessment of the psychological state of those who frequent it.

Perception, which involves our dominant sensory field of vision, ${ }^{54}$ is a special kind of interaction between man and his environment. A psychological model of the experience of beauty in something physically present might look like this:

\section{W (world or environment) $\longrightarrow S$ (stimulus) $\longrightarrow \mathrm{O}$ (our organism with its sense receptors, brain and muscles) $\longrightarrow \mathrm{R}$ (response) $\longrightarrow$ W (world) ${ }^{55}$}

Diagrammatically implicit in the $\mathrm{O}$ (organism) portion of this model is the ongoing character of perception as an action conditioned by the needs, values,

\footnotetext{
s Program for an Undergraduate Library

(Ann Arbor, Michigan: University of Michigan Library, n.d.) (mimeographed), p.2.

${ }^{54}$ Schweikher, op. cit., p.9.

${ }^{55}$ Victoria Kloss Ball, The Art of Interior Design: A Text in the Aesthetics of Interior Design (New York: Macmillan, 1960), p.2.
} 
and ideals of self, as well as the reality of the object perceived.

In general, tension is effectively resolved in a locale through the effective manipulation of colors and the proper use of illumination. It may be desirable, however, to introduce tension-creating opposition into certain portions of the library. Where reading areas are in or adjacent to the stacks, tension may be valuable in the vicinity of the social science collections, for example, as a means of heightening student sensitivity to the societal tensions being studied.56 As a general rule, the degree to which tensions need resolution is directly related to the extent of alienation in the student body.

Developments in academic libraries

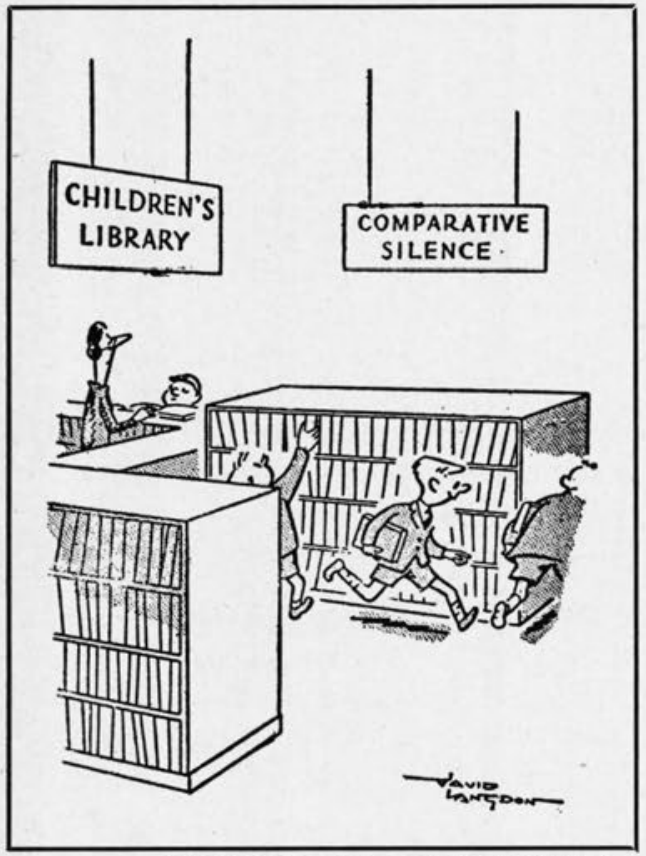

REPRODUCED BY PERMISSION OF Punch.

since the end of World War II, it should be recalled, have emphasized the need for anthropocentric perspectives. A combination of rising enrollments and inadequate physical facilities, to say nothing of the geometric progression of

* A theoretical suggestion made in Ibid., p.9. knowledge and new publication, has forced library administrators to emphasize output, to the almost total neglect of associated ends. Computers, closedcircuit television, reproducers, and charging machines are all part of a technology aimed at giving library users more rapid and thorough access to information. Recent developments in the library of the Chicago undergraduate division of the University of Illinois would seem to indicate that the completely automated library is just around the corner.

The application of technology to library operations demands, one feels certain, unusually good information on patterns of library and literature use. One wonders, nevertheless, whether the introduction of a machine might not require a psychological understanding of the human matrix of academic librarianship. The Council on Library Resources, which has so admirably supported the technological maturation of librarianship, has done little to promote projects of a sociological or psychological nature which are not immediately related to increased output. In his recent book, Science Since Babylon, Derek J. S. Price calculates that the scientific aspects of our culture are doubling every decade while similar progress in nonscience takes from thirty to fifty years. If this pattern holds, the information needs of scientists by the year 2000 will be sixteen times what they are now while our capacity, as librarians, to cope with the psychological issues posed by these needs will have increased but in the magnitude of one. It would seem only prudent to plan now for the psychological aftermath of automation.

Recently, while discussing the organizational and research problems of public librarianship, Paul Wasserman submitted that "if no agreement can be reached about [organizational] goals no one can ever agree about success or failure of performance." 57 It should be said,

\footnotetext{
${ }^{57}$ Wasserman, "Research Frontiers," Library Journal, LXXXVI, (July 1961), 2413.
} 
however, that where goals have been formulated by academic libraries they represent a far too narrow, unidimensional criterion of organizational success. Admittedly, there are those who regard the goal model of organizational performance as having significant validity because it "applies the values of the subject under study as the criterion of judgment." 58 Others, like Amitai Etzioni, have discerned serious problems in the goal model or organizational analysis: "Goals, as norms, as sets of meaningdepicting target states, are cultural entities. Organizations, as systems of coordinated entities of more than one actor, are social systems. There is a general tendency for cultural systems to be more consistent than social systems." 59

This inconsistency results from the general failure to endow social systems, like academic libraries, with sufficient resources, human and physical, to satisfy the goals set for them. Moreover, as social systems, academic libraries are multifunctional and devote some of their efforts to the meeting of goals, some to the acquisition of resources only indirectly related to the satisfaction of goals, and, finally, a substantial amount to their own maintenance and perpetuation. Consequently, if one desires to measure organizational success it may be better to view the organization as a functioning system rather than as an agency devoted exclusively to fulfilling a priori goals.

In the system model of analysis, one's effort is to learn whether an organization, like a library, has optimally allocated its resources to its manifold functions. If, for example, all resources were allocated to goal requirements, other organizational needs could hardly receive maximal satisfaction. ${ }^{60}$ Nominally, the goals of academic librarianship relate

* Amitai Etzioni, "Two Approaches to Organizational Analysis: A Critique and a Suggestion," Ad. ministrative Science Quarterly, V, (September 1960), 258 .

Ibid., pp.258-59.

0 Ibid., p.262. to preserving important materials and satisfying the information requirements of users. Although ancillary to its ostensible objectives, the establishment of library conditions that are psychically satisfying to users would seem fully as important.

Some support for the system model of library analysis comes from an effort by Richard L. Meier to establish efficiency criteria for a large state university library. Meier hypothesized that the library was handling messages at a rate which metropolitan areas would be forced to meet some time in the future. Equating marginal cost to the library of providing a unit of service with an estimate of the worth of the time students spend waiting for service to be provided, he suggested, as an optimization criterion, that "the sum of the marginal cost of providing a unit of service and the marginal cost for the user should be a minimum."61 In a tight goal model of library organization, such a criterion might seem quite tenable. The investigator learned, however, that all-out efforts to minimize the cost to libraries of providing service neglected the need for resource allocation to organizational improvement and to the restructuring of service in anticipation of demand. Meier's final criterion, still understated because of its failure to account for the requirement of a priori investment in anticipation of future demands, was that "improvements should be made in the quality and scale of service until the combined costs to the library and the user reached the value of the alternative uses for the time of the faculty and students." 62 In Meier's empirical validation of the system model, convincing evidence is presented that maximum output at minimum cost is an unsatisfactory stand-

\footnotetext{
61 Meier, "Efficiency Criteria for the Operation of Large Libraries," Library Quarterly, XXXI, (July 1961), 230.

${ }^{62}$ Ibid., p.234. For Meier's description of a range of responses which academic libraries might make to increasing communications loads, see his "Communications Overload: Proposals from the Study of a University Library," Administrative Science Quarterly, VII, (March 1963), 534-40.
} 
ard for libraries. Implicit in the investigator's final criterion, moreover, though couched in financial terms, is a recognition of the need to improve library operations qualitatively as a concession to the psychological needs of users.

At the outset, it was suggested that while the alienation of youth culture is generally related to the Larger Society, it may, nevertheless, be experienced to varying degrees in particular social institutions. It may, for example, be reduced or reinforced with reference to an academic library. Scales thus far developed to measure alienation, either societally or within the smaller context of the social system, set humanistic values (e.g., mastery and autonomy, insight and understanding, order and trust, consensus and commitment, and interplay and involvement) off against the variants of alienation (e.g., powerlessness, meaninglessness, normlessness, isolation, and selfestrangement). ${ }^{63}$ Sample items from a three-component, twenty-four-item scale for measuring societal alienation in Columbus, Ohio, were:

1. Powerlessness (9 items with .78 reliability) "There is little or nothing I can do toward preventing a major 'shooting' war." "We are just so many cogs in the machinery of life."

2. Normlessness (6 items with .73 reliability) "The end often justifies the means." "I often wonder what the meaning of life really is."

3. Isolation (9 items with .84 reliability) "Sometimes I feel all alone in the world." "One can always find friends if he shows himself friendly."

"Melvin Seeman and John W. Evans, "Alienation and Learning in a Hospital Setting," American Sociological Review, XXVII, (December' 1962), 772. Other types of alienation scales may be found in the follow. ing articles: (1) Gwynn Netler, "A Measure of Alienation," American Sociological Review, XXII, (Decem. ber 1957), 670-77; (2) Wendell Bell, "Anomie, Social Isolation, and the Class Structure," Sociometry, XX, (June 1957), 105-16; (3) Allan H. Roberts and Milton Rokeach, "Anomie, Authoritarianism, and Prejudice: A Replication," American Journal of Sociology, LXI, (January 1956), 355-58; and (4) Leo Srole, "Social Integration and Certain Corollaries: An Ex"Social Integration and Certain Corollaries: An ExXXI, (December 1956), 709-16.
(The 24 item Alienation Scale had a .78 reliability. ${ }^{64}$ )

In this study, the correlation among the three subscales, or variants of alienation, revealed each as sufficiently independent to merit treatment as an independent variable. All of these three variants are strong components of the youth culture.

Perhaps more important for our consideration are the alienation studies already completed on an agricultural cooperative $^{65}$ and a TB hospital. In their study of the hospital, Melvin Seeman and John W. Evans postulated that powerlessness, as a variant of alienation, was related to limited knowledge of the environment. "In an important sense," according to these researchers, "knowledge acquisition is irrelevant for those who believe that fate, luck, chance, or external forces control the fall of events." 66 When applied, their scale for powerlessness, which measured expectancies for control, ${ }^{67}$ revealed that low alienation was related to the quantity of one's information about TB and of the meaning of the hospital environment. On the basis of their research, Seeman and Evans proposed a broad hypothesis for social systems, namely that "differences in alienation (i.e., in powerlessness) are associated with the differential learning of behavior-relevant informa-

64 Dwight G. Dean, "Alienation: Its Meaning and Measurement," American Sociological Review, XXVI, (October 1961), 756.

es John P. Clark, "Measuring Alienation Within a Social System," American Sociological Review, XXIV, (December 1959), 851. In the Clark study, the outstanding correlate of alienation (at .62) was the members' level of dissatisfaction with the cooperative as an organization.

$\Leftrightarrow$ Seeman and Evans, op. cit., p.773.

67 Ibid., pp.774-75. In the Seeman-Evans study, powerlessness was measured by a scale of forcedchoice items developed at Ohio State University. The following are sample choices:

1. Becoming a success is a matter of hard work; luck has little or nothing to do with it.

Getting a job depends mainly on being in the right place at the right time.

2. Many times I feel I have little influence over the things that happen to me. $\mathrm{I}$ do not believe that chance and luck are very important in my life.

3. - The average citizen can have an influence on the way the government is run. The world is run by the few people in power, and there is not much the little guy can do about it. 
tion." 68 Based on this study, one might tentatively suggest that academic librarians can help counteract student alienation by insuring that students have a good understanding of the functions and purposes of the library. As the setting for learning moves away from the classroom, librarians should make a strong effort to make students as familiar with the raison d'être of the library as they are traditionally acquainted with the purposes of the classroom.

Thus far, our study of academic librarianship has utilized mainly the cultural and behavioral approaches, with rather little emphasis on the more usual ecological one. Librarians have used a first approximation of the latter approach when they have observed patterns of physical activity within and without their libraries (e.g., the hours of peak circulation, the relative use given various portions of the collection, the character of student traffic patterns as they relate to the positioning of a new library, etc.). In her seminal study of the use of the Knox College library, Patricia B. Knapp combined the ecological and behavioral perspectives when she associated library activity with student characteristics like (1) academic class;

scholastic achievement; (3) scholastic aptitude; and (4) sex. ${ }^{69}$

It is perhaps the failure to recognize the ecological aspects of Mrs. Knapp's style and the specificity of her locale that has caused many to overgeneralize her conclusions. The very essence of the ecological approach is its nonuniversal-

\footnotetext{
I Ibid., p.772. In a recent overview of studies on the diffusion of knowledge about science to the public, Wilbur Schramm of Stanford determined that such knowledge is widely but not deeply distributed in the United States. He ascertained that the depth of one's scientific knowledge was inversely related to one's feelings of foreboding about the scientific enterprise and that those who felt alienated with respect to science still had "a tendency to clothe science with magic and myth and for suspicions to develop." See Wilbur Schramm, "Science and the Public Mind" in Studies of Innovation and of Communication to the Public (Volume 2 of "Studies in the Utilization of the Behavioral Sciences") (Stanford, Calif. Stanford University Institute for Communication Research, 1962), p.265.

* Knapp, College Teaching and the College Library (ACRL Monograph No. 23) (Chicago: ALA, 1959),
} pp. 28-29. ity and its low validity for other than a particular institution at a given period of time. The universalizing of ecological conclusions can result in a dangerous imitation of corrective prescriptions. Given the current irrelevance of collegiate models provided by Europe, David Riesman has noted the tendency of colleges and universities to be isomorphic, or convergently imitative, of certain elite institutions with little or no consideration of how what is imitated will be congruent with local conditions. ${ }^{70}$

Why, for example, should Winona (Minnesota) State College use what Dartmouth has done as a prescription for action? Why should Catholic colleges currently abuilding use as models older institutions whose "owners" have been tempted to "identify the college with the religious community and to think of the students as a temporary part of the community"?71 Is it logical for institutions to construct a separate undergraduate library on the Harvard model without first ascertaining empirically the capacity or noncapacity of their students to use effectively a large open research collection like that of the Firestone library at Princeton? ${ }^{72}$ Because some state universities have decided to accommodate superior students in their undifferentiated student bodies by either internal (e.g., the Honors College at the University of Illinois) or external (e.g., Michigan State University at Oakland) decentralization does not mean that all colleges and uni-

\footnotetext{
${ }^{70}$ Riesman, Constraint and Variety in American Education (Garden City, N.Y.: Doubleday, 1958), pp.3536. Riesman's image is that of a snake whose middle and end segments look to the head for direction but never seem to get it.

${ }^{71}$ Andrew M. Greeley, Strangers in the House: Catholic Youth in America Today (New York: Sheed and Ward, 1961), pp.74-75. For an extensive discussion of "community ownership" of institutions of higher education, see James J. Maguire, "Family Affair," Commonweal, LXXV, (November 10, 1961), 171-73.

${ }^{72} \mathrm{I}$ am not certain that librarians generally have sufficient evidence of a hard sort regarding student capacities to give immediate assent to Ellsworth's proposition that "the youngsters in most universities aren't ready to work in a research library..." For Ellsworth's discussion of this issue, see Planning the College and University Library Buildina: A Book for Campus Planners and Architects (Boulder, Colo.,
} $1960)$, p.14. 
versities, by analogy, should construct separate facilities on a basis of the maximum overt participation of superior students only. All such decisions, including those relating to the establishment of library facilities, should be based on a better assessment of local conditions than has prevailed thus far.

Very recently, a student of higher education observed that the college is the "major socializing agency for the subculture of educated men." 73 If that is so, students are called upon to acquire some cultural sophistication during their college experience, a cultural sophistication which comprehends knowledge in some depth of the human situation and the concomitant ability "to respond to ideas on their own terms rather than as evaluations or prescriptions for action."74 Teachers and librarians must work together to help students to construct within themselves the commitments to society and ideas which underlie a valid cultural sophistication.

In nonresidential, working-class colleges and universities, where many students view themselves as youth apprentices who have already accepted societal life ways in their outside jobs, there is a need for improved student understanding of the worth of ideas and abstractions generally. Following is a hypothetical scheme of college-student subcultures devised by Martin Trow:

Involved with Ideas

$$
\begin{aligned}
& \text { Identify with } \\
& \text { their college } \\
& 12 \\
& 34
\end{aligned}
$$$$
(+) \quad(-)
$$

ข Martin Trow, "Cultural Sophistication and Higher Education" in Selection and Educational Differentiation (Berkeley, Calif.: University of California Field Service Center and Center for the Study of Higher Education, 1959), p.107.

7 Ibid., pp.109-10.

75 Trow, "The Campus Viewed as a Culture," in
It should be indicated that in the Trow scheme, the greatest threat to the academic subculture (where there is both involvement with ideas and identification with the college) is not from the collegiate subculture (where, despite the enchantment with football and fraternities, there remains identification with the institution) but from the vocational subculture where alienation can derive from a lack of ideological or social roots in the college rather than as a consequence of the rejection of adult life styles, to which most vocationalists, as part-time employees, have already subscribed. ${ }^{76}$ It must be pointed out, however, that the kind of alienation felt by the apprentice vis-àvis his college does not have nearly the power of the alienation felt by the youth culturalists in the institutions where there is a strong academic and/or nonconformist orientation. Let it be said, finally, that forces in our "white collar" society do not permit us the luxury of reducing felt alienation by making all youths apprentices.

As librarians concerned with the rectitude of our acquisition policies and patterns of service, our effort should be toward some assessment of the character of the balance between youth culture and youth apprenticeship in our institutions. William G. Land, a Washington, D.C., educational analyst, has now devised a continuum suitable to our needs which, as initially used, describes the educational orientations of one hundred (Continued on page 307)

Hall T. Sprague (ed.), Research on College Students (Boulder, Colo.: Western Interstate Commission for Higher Education and the Center for the Study of Higher Education of the University of California (Berkeley), 1960), p.111.

"I In an unpublished paper, two University of California (Berkeley) investigators have reported a study of students on the Berkeley campus which attempts to measure the impact of school spirit on scholarship. They discovered that although the school spirited are less interested in intellectual thought for its own sake than are the strict academic subculturalists, nevertheless, "school spirit has no effect on the amount of time spent in studying, the motivation to get good grades, or grades high enough to remain in school. and it has only slight effect on the attainment of top grades." See Robert Wenkert and Hanan Selvin, "School Spirit and the Spirit of Scholarship," un. published manuscript, University of California (Berkeley) Survey Research Center (January 1962), p.21. 